\section{Recovery from punishment as a function of deprivation level*}

\author{
LARRY MacDONALD and ALAN BARON \\ University of Wisconsin-Milwaukee, Milwaukee, Wis. 53201
}

Rats lived in an operant conditioning chamber where maintenance water was continuously available as a consequence of leverpressing. Under these conditions of very low deprivation, a 1-day period of shock punishment severely suppressed responding. To observe the influence of increased motivation on recovery from punishment, Ss were deprived of water outside the chamber for 0,24 , or $72 \mathrm{~h}$ and then returned for a 3-day observation period with the punishment contingency removed. Ss that were not water-deprived at the start of recovery had relatively long recovery latencies, requiring about $28 \mathrm{~h}$ on the average to resume responding. By comparison, Ss that were either 24 or $72 \mathrm{~h}$ water-deprived required less than half that time to recover. The results were interpreted as supporting a conflict analysis of the effects of deprivation on recovery from punishment.

In the study of punishment, considerable attention has been devoted to such variables contributing to the suppressive effectiveness of a punishing stimulus as the intensity of the stimulus, the temporal relationship of the stimulus to the response, and the schedule of presentation of the stimulus (cf. Azrin \& Holz, 1966). Less well understood are variables which may influence recovery from punishment, i.e., variables which determine the rate at which the punished response will gain in strength after removal of the punishment contingency.

Estes's early work (1944) suggested that an important variable in recovery from punishment was the degree of exposure to the situation in which punishment was encountered. This study, and subsequent investigations (e.g., Baron, 1965; Boe \& Church, 1967), showed that confinement in the situation, as well as opportunity to engage in nonpunished behavior, accelerated the recovery process. Another variable pertains to the intensity of the punishing stimulus. It has been reported that if punishment is sufficiently intense, suppression of behavior may be quite long-lasting (Boe \& Church, 1967) and, in some instances, recovery may not occur at all (Azrin, Holz, \& Hake, 1963).

The present experiment was concerned with the potential role of a third variable: level of motivation at the time of recovery. In what may be the only published study directly concerned with this question, Boroczi, Storms, \& Broen (1964) compared

\footnotetext{
* This research was supported by Research Grant GB 8234 from the National Science Foundation and by the Graduate School of the University of Wisconsin-Milwaukee. Requests for reprints should be sent to Alan Baron, Department of Psychology. University of Wisconsin-Milwaukee, Milwaukee, Wis. 53201 .
}

recovery rates of two groups of rats whose food-reinforced leverpressing had been suppressed by shock punishment. No difference was obtained between the recovery rates of a group maintained at a constant level of food deprivation ( $23 \mathrm{~h}$ ) during each of three recovery sessions and a group whose deprivation level increased from $23 \mathrm{~h}$ during the first session to 47 and $71 \mathrm{~h}$ during the subsequent two. Brown, Anderson, \& Brown (1966), by comparison, showed that the severity of an approach-avoidance conflict is influenced by deprivation levels at the time of testing. In their experiment, rats that had been both fed and shocked in the goalbox of an alley at a low level of food deprivation ran farther down the alley when tested at a higher level. While this finding is suggestive about the effects of motivational level on recovery, it should be noted that the entire course of recovery was not observed and, further, that goalbox aversiveness was established by placing Ss directly in the goalbox and shocking them there rather than through the procedure of punishing approach responses to the goalbox.

In the present experiment, rats were punished with electric shock while responding for water, and then recovery was observed under either the same or increased levels of water deprivation. Two unusual features of the procedure were that punishment was administered under conditions of very low drive and that animals lived in the experimental apparatus, thus permitting continual observation of recovery.

The Ss were 19 male albino rats, 90-130 days old, obtained from the Holtzman Co., Madison, Wisconsin.

\section{APPARATUS}

Sessions were conducted in four leverpressing units (Lehigh Valley,
1316). The chamber of each unit, $30 \times 20 \times 19 \mathrm{~cm}$, was of plastic construction except for the grid floor and the metal front and rear walls. A single response lever protruded through one metal wall approximately $2.5 \mathrm{~cm}$ above the grid floor and $5 \mathrm{~cm}$ to the left of a centrally located opening through which a .01-cc dipper could be raised. The grid floor could be charged from a shock generator (Grason-Stadler, E1064) which delivered current to different pairs of grid bars in rapid alternation. A white-jeweled lamp (1.1 W) was mounted on the wall $6 \mathrm{~cm}$ above the lever, and a larger and brighter lamp (7.6 W), providing general illumination, was located immediately outside the chamber. A speaker outside the chamber delivered a 75 . $( \pm 1)$ dB masking noise. Two modifications were made of the conditioning chamber: (1) a wire basket in which food could be placed was suspended from the Plexiglas ceiling at the end opposite the lever, and (2) the size of the dipper drawer was increased to hold a larger quantity of water. Programming and recording equipment were located in an adjoining room.

\section{PROCEDURE}

Except as noted below, Ss lived in the conditioning chambers throughout the experiment. Within the chambers, dry food was always available in the basket, but water was obtained only as a consequence of leverpressing. Leverpressing was reinforced on a $50 \%$ random schedule, with each reinforcement consisting of a 2 -sec presentation of the water-filled dipper. Leverpresses also turned on the light above the lever for $2 \mathrm{sec}$, during which time additional responses had no consequences. In order that the chamber could be cleaned and resupplied, Ss were removed and placed in individual holding cages for $1 \mathrm{~h}$ each day. During this hour, Ss had free access to dry food and water.

The experiment consisted of five phases: baseline, punishment, deprivation, recovery, and deprivation control.

Baseline

Following acquisition of the leverpress response, Ss were observed in the conditioning chamber for 10 days, by which time stable rates of responding had occurred.

\section{Punishment}

On Day 11, shock punishment was programmed to occur during the entire 23 -h session following the $50 \%$ of the leverpresses that were not reinforced. The shock had an intensity of $1.0 \mathrm{~mA}$ and a duration of $0.5 \mathrm{sec}$.

\section{Deprivation}

At the end of the punishment session, Ss were returned to the 


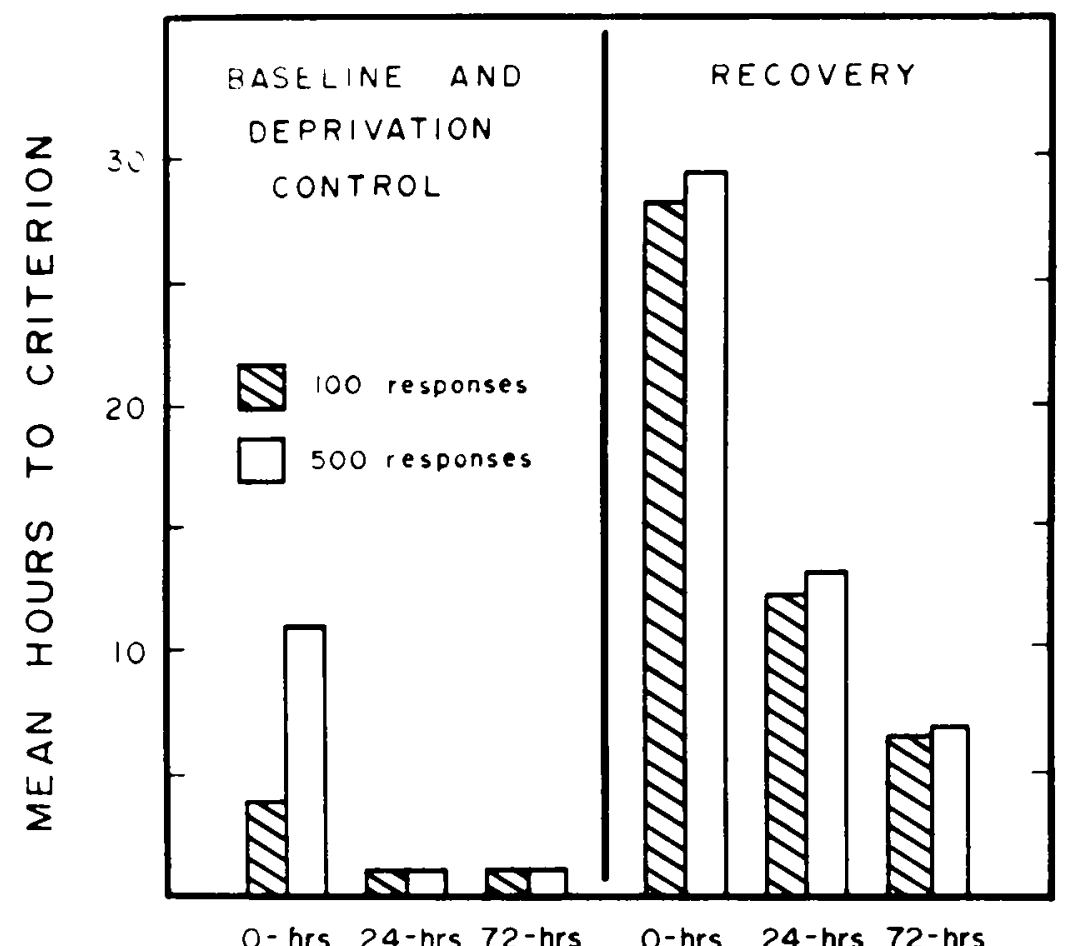

HOURS OF WATER DEPRIVATION

Fig. 1. Mean hours to reach criteria of 100 and 500 responses as a function of deprivation level and condition of testing. Left panel shows response latencies during baseline conditions; right panel shows response latencies during recovery from punishment.

holding cages, where they remained for 3 days $(73 \mathrm{~h})$. During this time, a 0 -h-deprived group $(\mathrm{N}=6)$ had continual access to water, a 24-h-deprived group ( $N=6)$ received water for 2 days and no water for the third day, and a 72-h-deprived group $(\mathrm{N}=7)$ received water for the first hour and no water for the remaining 3 days. Food was available throughout the deprivation period.

Recovery

The Ss were then returned to the conditioning chambers, where they remained for 3 consecutive days. Leverpressing was no longer punished, and the schedule of water reinforcement was the same as during the baseline phase. Animals were not disturbed during the $72-\mathrm{h}$ recovery period, except for replacement of water in the dipper drawer as needed. Deprivation Control

The purpose of this phase was to evaluate the effects of water deprivation on nonsuppressed behavior. After Ss completed the recovery phase, by which time they had returned to their prepunishment baselines, they were given 2 days of free access to water in the holding cages. Following an additional baseline day in the conditioning chambers, Ss were deprived in the holding cages for either 24 or $72 \mathrm{~h}$ over a 3 -day period and then returned to the chambers. The first eight $S$ s observed in this phase of the experiment (four after $24 \mathrm{~h}$ of deprivation and four after $72 \mathrm{~h}$ of deprivation) responded at high rates within a few minutes after reintroduction into the chamber; therefore, it was decided not to continue this phase with the remaining Ss.

Number of leverpresses was recorded in 1-h blocks. By the end of the baseline phase, Ss were averaging about 1,100 responses during the $23-h$ sessions. Introduction of the punishment condition on Day 11 had the effect of rapidly and severely suppressing response rates; on this day, the total number of responses did not exceed 14 for any animal.

Subsequent recovery from the effects of punishment during the recovery phase was found to be an all-or-none affair; i.e., after a period when few or no responses were made, Ss abruptly began to respond at high rates. Since the initial burst of responding usually involved 100 or more responses, the results were examined from the standpoint of

\section{RESULTS}

elapsed time (to the nearest hour) required for completion of at least 100 responses. Also analyzed were times required to complete 500 responses.

A summary of the data may be seen in Fig. 1. For comparative purposes, the left panel shows response latencies as a function of deprivation when behavior was not suppressed by punishment, i.e., times required to attain the 100 and 500 response criteria during the last day of baseline training ( $0 \mathrm{~h}$ deprivation) and during the deprivation control phase at 24 and $72 \mathrm{~h}$ of deprivation. It is apparent that in the absence of punishment, deprivation levels influenced the rate at which the criteria were attained. Thus, the baseline data indicate that under conditions of $\mathbf{0 ~ h}$ of deprivation, approximately $4 \mathrm{~h}$ were required, on the average, for completion of 100 responses, and more than $10 \mathrm{~h}$ were required for completion of 500 responses. By comparison, deprivation of either 24 or $72 \mathrm{~h}$ resulted in latencies that were considerably shorter $(p<.05)$, and, as the figure shows, both criteria were attained within the first hour after start of the session.

The right panel of Fig. 1 shows the recovery latencies as a function of deprivation level after the behavior had been suppressed by punishment. Here it can be seen that latencies following punishment were longer than corresponding latencies when behavior had not been suppressed, and further, that recovery rates also varied as a function of deprivation. Under the 0 -h condition, recovery from punishment was quite slow, with a mean time of about $28 \mathrm{~h}$ required to attain the 100-response criterion. At the higher levels of 24 and $72 \mathrm{~h}$ of deprivation, recovery was considerably more rapid, occurring within 12 and $7 \mathrm{~h}$, respectively. Also apparent is that the response rates were quite high at the point of recovery, since in each of the punishment groups the 500-response criterion was attained within about $1 \mathrm{~h}$ following attainment of the 100-response criterion. Statistical comparisons established the reliability of differences between recovery under $0 \mathrm{~h}$ of deprivation and recovery when deprivation was either 24 or $72 \mathrm{~h}(\mathrm{p}<.05)$. While the right panel shows that the $72 \cdot h$ group recovered more rapidly, on the average, than the $24-\mathrm{h}$ group, this difference, as was the case when behavior was not suppressed (left panel), was not reliable.

Figure 1 shows that while deprivation facilitated recovery from the suppressive effects of punishment, deprivation levels in the range studied did not completely offset the effects of punishment. Thus, when 
deprivation was either 24 or $72 \mathrm{~h}$, recovery latencies following suppression were still longer than latencies when behavior had not been suppressed by punishment $(\mathrm{p}=.05)$. DISCUSSION

To account for their finding that Ss at different levels of deprivation recovered from punishment at equal rates, Boroczi et al (1964) suggested that the exclusive factor determining recovery was degree of exposure to the apparatus. Such exposure, which was held constant in their experiment, was assumed to provide opportunity for extinction of aversive properties of apparatus cues and approach behavior. An alternative account, emphasizing the role of motivation in recovery from punishment, is suggested by the finding of Brown et al (1966), that increased deprivation facilitated resolution of an approach-avoidance conflict. An analysis of recovery from punishment in terms of conflict theory (Miller, 1959) suggests that rate of recovery depends upon the severity of a conflict stemming from the aversive and reinforcing consequences of the punished response. According to this position, deprivation by raising the approach gradient would be expected to facilitate resolution of the conflict. Obviously, degree of exposure as a factor which would lower the avoidance gradient also would contribute in a major way to recovery.

The procedures of the present experiment held degree of exposure constant and varied deprivation level. Under these conditions, deprivation facilitated recovery from punishment. The findings, then, are consistent with a conflict interpretation and are contrary to the contention that degree of exposure is the exclusive factor determining recovery from the effects of punishment.

Finally, it is worth noting that while the present experiment showed more rapid recovery at $24 \mathrm{~h}$ of deprivation than at $0 \mathrm{~h}$, further increases in deprivation to $72 \mathrm{~h}$ did not enhance recovery rates to any significant degree. This finding suggests that the results of the Brown et al and Boroczi et al experiments may not be contradictory, since Brown et al compared high $(44 \mathrm{~h})$ and very low $(1 \mathrm{~h})$ degrees of food deprivation, whereas Boroczi et al compared only relatively high levels of deprivation $(23,47$, and $71 \mathrm{~h})$.
REFERENCES

AZRIN. N. H.. \& HOLZ, W. C. Punishment. In W. K. Honig (Ed.). Operant behavior: Areas of research and application. New York: Appleton-Century-Crofts, 1966. Pp. 380-447.

AZRIN, N. H., HOLZ, W. C., \& HAKE, D. Fixed-ratio punishment. Journal of the Experimental Analysis of Behavior, 1963, 6. 141-148.

BARON, A. Delayed punishment of a runway response. Journal of Comparative \& Physiological Psychology, 1965,60, $131-134$.

BOE, E. E., \& CHURCH, R. M. Permanent effect of punishment during extinction. Journal of Comparative \& Physiological Psychology, 1967, 63, 486-492.

BOR OCZI, G.. STORMS, L. H., \& BROEN, W. E., JR. Response suppression and recovery of responding at different deprivation levels as functions of intensity and duration of punishment. Journal of Comparative \& Physiological Psychology, 1964, 58, 456-459.

BROWN, J. S., ANDERSON, D. C., \& BROWN, C. S. Conflict as a function of food-deprivation time during approach training, avoidance training, and conflict tests. Journal of Experimental Psychology, 1966, 72, 390-400.

ESTES, W. K. An experimental study of punishment. Psychological Monographs, 1944,57 (3, Whole No. 263).

MILLER, N. E. Liberalization of basic S-R concepts: Extensions to conflict behavior, motivation, and social learning. In S. Koch (Ed.), Psychology: A study of a science. Vol. 2. New York: McGraw-Hill, 1959. Pp. 196-292.

\section{CURRENT LITERATURE ON AVOIDANCE \& PUNISHMENT IN ANIMALS}

BINTZ, J. (University of California, Davis, Calif. 95616). Effect of shock intensity on the retention of an avoidance response. Psychonomic Science, 1971, 22, 17-18.

BOOTH, J. H., \& HAMMOND, L. J. (Temple University, Philadelphia, Pa. 19122 ). Configural conditioning: Greater fear in rats to compound than component through overtraining of the compound. Journal of the Experimental Psychology, 1971, 87, 255-262.

CAHOON, D. D. (Auburn University, Auburn, Ala. 36830), CROSBY, R. M., DUNN, S., HERRIN, M. S., HILL, C. C. \& McGINNIS, M. The effect of food deprivation on shock elicited aggression in rats. Psychonomic Science, 1971, 22, 43.44.

CICALA, G. A. (University of Delaware, Newark, Del. 19711), ULM, R. R., \& DREWS, D. R. The effects of shock intensity and intertrial interval duration on the operant level of a shuttle-avoidance response. Psychonomic Science, 1971, 22, 7-8.

DAVENPORT, D. G. (St. Louis University, St. Louis, Mo. 63103), OLSON, R. D., \& OLSON, G. A. Preliminary analysis of partial reinforcement in discriminated avoidance. Psychonomic Science,
$1971,22,9-11$.

GILBERT, R. M. (Alcoholism and Drug Addiction Research Foundation, Toronto 179 , Ontario, Canada). Signal functions in discriminated avoidance behavior. Journal of the Experimental Analysis of Behavior, 1971, 15, 97-108.

GROSSEN, N. E. (Sacramento State College, Sacramento, Calif. 95819). Effect of aversive discriminative stimuli on appetitive behavior. Journal of Experimental Psychology, 1971, 88, 90-94.

HOUTEN, R. V. (Dalhousie University, Halifax, Nova Scotia, Canada), \& RUDOLPH, R. Summation of punishment suppression. Journal of the Experimental Analysis of Behavior, 1971, 15, 117-121.

MANKINS, S. L. (Bowling Green State University, Bowling Green, Ohio 43402), \& RAGUSA, D. M. Effects of interpolated escape training on discriminated leverpress avoidance. Psychonomic Science, 1971, 22, 15-16.

MATTHEWS, T. J. (New York University, University Heights, New York, N.Y. 10453), MORIN, L. P., \& $\mathrm{CHURCH}$, R. M. Avoidance of thermal stimuli in the rat. Psychonomic Science, 1971, 22, 59.60.
MISANIN, J. R. (Susquehanna University, Selinsgrove, $\mathrm{Pa} .17870$ ), SMITH, N. F., \& MILLER, R. R. Memory of electroconvulsive shock as a function of intensity and duration. Psychonomic Science, 1971, 22, 5-7.

OLSON, R. D., DAVENPORT, D. G. (St. Louis University, St. Louis, Mo. 63103), \& KAMICHOFF, N. C. Discriminated avoidance and the partial reinforcement effect. Psychonomic Science, 1971, 22, 12-14.

POWELL, R. W. (Department of Behavioral Science, University of South Florida, Tampa, Fla. 33620). Some effects of punishment shock intensity upon discriminative responding. Journal of the Experimental Analysis of Behavior, 1971, 15, 109-116.

RACHLIN, H. (State University of New York at Stony Brook, Stony Brook, N.Y. 11790), \& LOVELAND, D. Titration of punishment. Psychonomic Science, 1971, 22, 39-40.

STEIN, N. (Syracuse University, Syracuse, N.Y. 13210), HOFFMAN, H. S., \& STITT, C. Collateral behavior of the pigeon during conditioned suppression of key pecking. Journal of the Experimental Analysis of Behavior, $1971,15,83-93$. 